\title{
Clinical and CSF studies in newborn infants with neurological abnormalities
}

\author{
S. W. DE SOUZA and R. D. G. MILNER \\ From the Department of Child Health, University of Manchester and St. Mary's Hospital, Manchester
}

\begin{abstract}
De Souza, S. W., and Milner, R. D. G. (1974). Archives of Disease in Childhood, 49, 351. Clinical and CSF studies in newborn infants with neurological abnormalities. Thirty-four infants with abnormal neurological signs of no specific aetiology and 49 infants without abnormal neurological signs were selected in the newborn period. After a detailed neurological examination, the hyperexcitability syndrome was diagnosed in 18 and the apathy syndrome in 16 infants. The apathy syndrome was associated with apnoeic attacks, absent sucking, swallowing, and Moro responses as well as pneumonia. The hyperexcitability syndrome was associated with a history of fetal distress, a very poor condition at birth, and also absent sucking and swallowing responses. 3 infants with the apathy syndrome died. The majority of abnormal infants had either blood-stained or xanthochromic CSF. Cisternal puncture was helpful in diagnosing intracranial haemorrhage and was associated with subsequent clinical improvement in 6 infants. Though there was an association between apathy and hyperexcitability syndromes in the newborn period and subsequent neurological abnormalities during the first year, these abnormalities were present only in a minority. This study shows that the clinical diagnosis of the apathy or hyperexcitability syndrome in the newborn period has diagnostic and prognostic significance.
\end{abstract}

In recent years a number of studies have shown an association between abnormal neurological signs in newborn infants and neurological abnormalities in later childhood (Prechtl, 1960, 1965; Smithells, 1961; Dargassies, 1962; del Mundo-Vallarta and Robb, 1964; Schulte, Filipp, and Michaelis, 1965; Amiel-Tyson, 1969; Brown, Cockburn, and Forfar, 1972). However, the prognostic value of many abnormal neurological signs in the newborn period has been disputed in a study by Donovan, Coues, and Paine (1962). The signs are due to alterations in muscle tone, reflexes, posture, and co-ordination as well as convulsive seizures. They could imply cortical or subcortical brain dysfunction associated with either structural or metabolic brain damage. In some newborn infants combinations of signs appear which are said to be easy to recognize; these are the 'apathy syndrome', 'hyperexcitability syndrome', and 'hemisyndrome' (Prechtl, 1965, 1967, 1968).

In the present study a group of newborn infants with abnormal neurological signs were investigated.

Received 8 November 1973.
The aims of the study were to identify newborn infants with the syndromes described by Prechtl (1965) and to examine inter-relations between them and (a) certain factors in the prenatal, natal, and postnatal period; (b) alterations in the composition of the CSF; (c) the diagnostic and therapeutic value of removing CSF by cisternal puncture and thus possibly reducing intracranial pressure; and (d) the incidence of neurological abnormalities during the first year. Cisternal rather than lumbar punctures were performed since blood-stained CSF obtained by cisternal puncture is unlikely to be due to trauma. In addition, relatively large quantities of CSF can be removed by cisternal puncture. The observations upon which this study is based were made over 3 years.

\section{Patients and methods}

Infants. A detailed neurological examination and cisternal puncture were carried out (S.W.De S.) in the early newborn period on 34 infants born at St. Mary's Hospital. These infants were selected (R.D.G.M.) on the basis that they were seriously abnormal neurologically but had no specific diagnosis, and that a cisternal 
puncture might be of diagnostic and therapeutic value. 49 infants randomly selected of similar gestational age and body weight with no abnormal neurological signs, born during the same period, were also studied. This group is subsequently referred to as 'normal'. Gestational age was estimated from the last menstrual period and confirmed in the normal infants by the presence or absence of certain neonatal reflexes (Robinson, 1966). The clinical condition of infants one minute after birth was assessed by examining three parameters, i.e. heart rate, respiration, and skin colour. The method of scoring used is shown in Table I; thus

\section{TABLE I}

Method of scoring when evaluating the condition of infants immediately after birth

\begin{tabular}{|c|c|c|c|}
\hline \multirow{2}{*}{ Sign } & \multicolumn{3}{|c|}{ Score } \\
\hline & 0 & 1 & 2 \\
\hline $\begin{array}{l}\text { Heart rate (per } \mathrm{min} \text { ) } \\
\text { Respiration } \\
\text { Colour }\end{array}$ & $\begin{array}{l}\quad<60 \\
\text { Absent } \\
\text { White }\end{array}$ & $\begin{array}{l}60-120 \\
\text { Gasping } \\
\text { Blue }\end{array}$ & $\begin{array}{l}>120 \\
\text { Regular } \\
\text { Pink }\end{array}$ \\
\hline
\end{tabular}

each infant could have scores ranging from $0-6$. The subsequent progress of all infants was carefully followed by regular clinical examinations and relevant laboratory and radiological investigations. Necropsy examination was carried out on all infants who died. After discharge from hospital infants were seen at intervals at an infant welfare clinic. Body weight and head circumference were measured routinely and normal development and medical problems were assessed.

Neurological examination. Infants were 3 to 160 hours of age and examinations were carried out 2 to 3 hours after a feed. Examinations were performed in a quiet room with the infant lying on a table. Conditions were standardized, including 'states' (predominantly 3-5) as described by Beintema (1968). Head and neck, trunk, and lower limbs were examined in that order, and posture, behaviour, muscle tone, and reflex responses (tendon, superficial, and neonatal) were assessed. Arousal or pacifying manoeuvres were $n \geq c e s s a r y$ from time to time when the infant was not in an optimal state. From the results, the apathy syndrome, the hyperexcitability syndrome, or the hemisyndrome was diagnosed by the following criteria.

(1) Apathy syndrome. Hypokinesis, hypotonia, and sluggish reflexes.

(2) Hyperexcitability syndrome. Increased spontaneous activity and tone and brisk reflexes.

(3) Hemisyndrome. Asymmetry in tone, spontaneous activity, and reflexes between the right and left sides.

Cisternal puncture. Cisternal puncture was carried out as described by Davies et al. (1972) shortly after the neurological examination. 3 to $5 \mathrm{ml} \mathrm{CSF} \mathrm{was}$ removed. The rate of flow was controlled by partially reinserting the stylet. Careful attention was given to the condition of the infant during the procedure and for at least 3 hours afterwards. Any change in the infant's condition was confirmed by clinical examination 3 hours after cisternal puncture.

Laboratory investigations. (1) Protein and glucose levels and cell counts were estimated on all CSF specimens which were also cultured for bacteria. Protein was determined by the method of Meulemans (1960) and glucose by the glucose-oxidase method. (2) Blood glucose and serum calcium levels were estimated on specimens of blood obtained either by heel-prick or from the umbilical vein. Blood glucose was determined by the glucose-oxidase method and serum calcium by atomic absorption spectrophotometry. (3) $\mathrm{pH}, \mathrm{Po}_{2}$, and $\mathrm{PCO}_{2}$ in umbilical arterial or arterialized capillary blood were estimated using Astrup apparatus (Radiometer Copenhagen BMS 3). (4) Swabs taken from the nose, throat, umbilicus, and rectum, and blood and urine specimens were cultured for either bacteria or viruses.

Radiological investigations. These included skull and chest $x$-rays.

\section{Results}

Of the 34 neurologically abnormal infants, 16 had the apathy syndrome and the remaining 18 had the hyperexcitability syndrome. The hemisyndrome was not present in any of these infants.

Prenatal factors. Certain factors associated with neurologically abnormal and normal infants were reviewed (Table II). All the mothers had received analgesics and sedatives during labour; these included morphia, pethidine, papaverine, promethazine, quinalbarbitone, amylobarbitone, diazepam, nitrazepam, and haloperidol. 3 mothers whose babies developed the hyperexcitability syndrome and 2 mothers whose babies developed the apathy syndrome received pethidine and promethazine during the second stage of labour. Mothers who had a caesarean section received a general anaesthetic (nitrous oxide, oxygen, and succinyl choline). 1 mother took an overdose of aspirin when she went into labour (attempted suicide); later the liquor was blood-stained and the cord blood acetylsalicylate level was $37 \mathrm{mg} / 100 \mathrm{ml}$.

Fetal distress was diagnosed when the fetal heart rate was less than $100 / \mathrm{min}$ or greater than $160 / \mathrm{min}$ associated with meconium-stained liquor. A history of fetal distress was present in significantly larger numbers of infants with the hyperexcitability syndrome, 12 of 18 , as compared with either infants with the apathy syndrome, 1 of 16 , or normal infants, none of 49. Prolapse of the cord occurred 
TABLE II

Prenatal factors associated with neurologically abnormal and normal newborn infants

\begin{tabular}{|c|c|c|c|}
\hline & \multicolumn{3}{|c|}{ No. or mean $\pm S E M$} \\
\hline & $\begin{array}{l}\text { Hyperexcitability } \\
\text { syndrome }\end{array}$ & Apathy syndrome & Normal \\
\hline No. of infants & 18 & 16 & 49 \\
\hline $\begin{array}{l}\text { Prenatal factors } \\
\text { Induced labour } \\
\text { Drugs: analgesics/sedatives } \\
\text { General anaesthesia (nitrous oxide, } \\
\text { oxygen, succinyl choline) } \\
\text { Aspirin overdose } \\
\text { Fetal distress } \\
\text { Cord prolapse } \\
\text { Length of labour (hr) } \\
\text { Forceps delivery } \\
\text { Caesarean section }\end{array}$ & $\begin{array}{c}6 \\
18 \\
3 \\
1 \\
12^{\star} \\
2 \\
9 \cdot 1 \pm 1 \cdot 3 \\
3 \\
3\end{array}$ & $\begin{array}{c}2 \\
16 \\
3 \\
\overline{1} \\
8 \cdot 2 \pm 0 \cdot 9 \\
\overline{1} \\
3\end{array}$ & $\begin{array}{c}7 \\
49 \\
3 \\
\overline{5} \\
2 \\
8 \cdot 6 \pm 0 \cdot 9 \\
7 \\
3\end{array}$ \\
\hline
\end{tabular}

* Significant increase in fetal distress in infants with the hyperexcitability syndrome compared with either infants with the apathy syndrome or normal infants $\left(P<0.01, \chi^{2}\right.$ test).

in 5 mothers whose labour was terminated either by caesarean section or breech extraction.

Condition after birth. The scores given to infants one minute after birth are shown in Table III. Infants with scores of $0-1$ were deemed to be in poor condition, whereas those with scores of 5-6 were said to be in good condition. A significant number of infants, 7 of 18 , with scores of $0-1$ developed the hyperexcitability syndrome. In contrast, a significant number of normal infants, 19 of 49, had scores of 5-6 compared with the other two groups. Resuscitative measures were necessary in all infants with scores of 0-4. These consisted of mucus extraction and administration of oxygen either by face-mask or through an endotracheal tube. In addition, some infants were given nalorphine, THAM, sodium bicarbonate, or glucose into the umbilical vein through an indwelling catheter.

TABLE III

Scores one minute after birth

\begin{tabular}{l|c|c|c}
\hline & $\begin{array}{c}\text { Hyperexcitability } \\
\text { syndrome }\end{array}$ & $\begin{array}{c}\text { Apathy } \\
\text { syndrome }\end{array}$ & Normal \\
\hline $\begin{array}{l}\text { No. of infants } \\
\text { Scores } \\
0-1 \\
2-4 \\
5-6\end{array}$ & 18 & 16 & 49 \\
& $77^{\star}$ & 1 & 0 \\
& 0 & 15 & 30 \\
\hline
\end{tabular}

*Scores $0-1$ occurred significantly more often in infants with the hyperexcitability syndrome compared with normal infants $\left(P<0.001, \chi^{2}\right.$ test).

+Scores 5-6 occurred significantly more often in normal infants compared with infants with either the hyperexcitability or apathy syndrome ( $P<0.005, x^{2}$ test.)
Age of onset and duration of neurological abnormalities. These were similar in infants with apathy and hyperexcitability syndromes (Table IV). The overall age of onset and duration of neurological abnormalities in the whole group were as follows. Age of onset, $<3$ hours 36\%, 3-12 hours $32 \%,>12$ hours $32 \%$; duration, $<48$ hours $12 \%, 48-72$ hours $38 \%,>72$ hours $50 \%$.

Clinical findings before cisternal puncture. Certain associated clinical findings in infants with either the apathy or hyperexcitability syndrome are shown in Table V. The apathy syndrome was present in 7 infants whose birthweights were less than 2500 g. 5 of these infants were premature (gestational age 34-36 weeks), and the other 2 were small-for-dates (birthweight less than the 10th centile, Butler and Alberman, 1969). In comparison, the birthweight was less than $2500 \mathrm{~g}$ in 7 of

TABLE IV

Age of onset and duration of abnormal neurological signs

\begin{tabular}{l|c|c}
\hline & $\begin{array}{c}\text { Hyperexcitability } \\
\text { syndrome }\end{array}$ & $\begin{array}{c}\text { Apathy } \\
\text { syndrome }\end{array}$ \\
\hline $\begin{array}{l}\text { No. of infants } \\
\text { Onset of neurological } \\
\text { abnormality (hr) }\end{array}$ & 18 & 16 \\
$<3$ & 6 & 6 \\
$3-12$ & 6 & 5 \\
$>12$ & 6 & 5 \\
& & \\
Duration (hr) & 2 & 2 \\
$<48$ & 6 & 7 \\
$48-72$ & 10 & 7 \\
$>72$ & & \\
\hline
\end{tabular}


TABLE V

Clinical findings before cisternal puncture

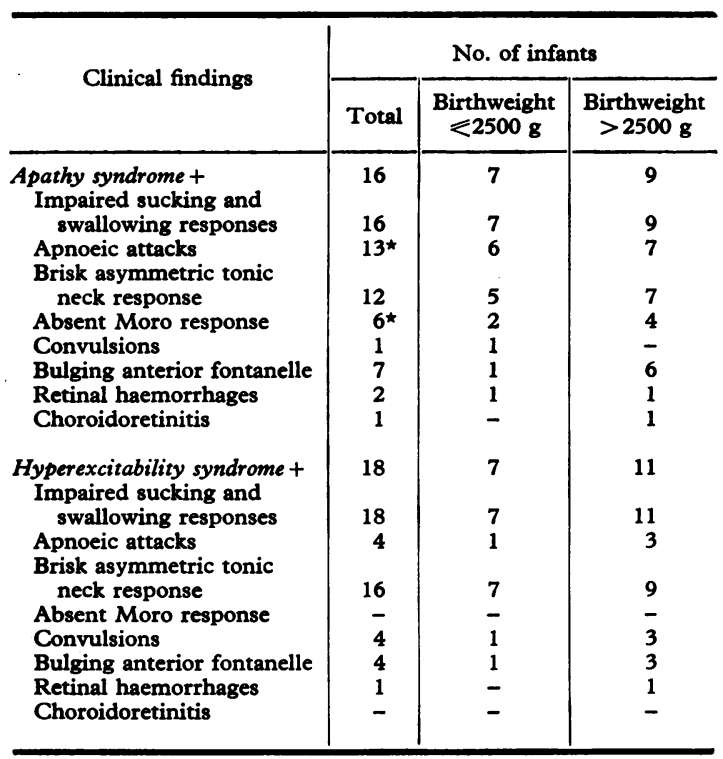

*Significant increase in apnoeic attacks or absent Moro response in infants with the apathy syndrome compared with infants with the hyperexcitability syndrome ( $P<0.01, \chi^{2}$ test).

the infants with the hyperexcitability syndrome. 4 were premature (gestational age 33-36 weeks) and the others were small-for-dates. Sucking and swallowing reflexes were impaired in all abnormal infants who were therefore fed through a nasogastric tube or intravenously for 24 to 96 hours. Apnoeic attacks were present in a significantly larger number of infants, 13 of 16 , with the apathy syndrome compared with 4 of 18 infants with the hyperexcitability syndrome. These attacks lasted from 30 to 60 seconds and were associated with cyanosis and a bradycardia of below 80 per minute. Normal respiration was restored by stimulation or intubation and intermittent positive pressure ventilation. An absent Moro response was also a significant finding in 6 of 16 infants with the apathy syndrome compared with none of the 18 infants with the hyperexcitability syndrome.

Alterations in CSF. Blood-stained CSF usually spurted from the needle and then flowed in a steady stream for a few seconds during which the stylet was reinserted and the flow reduced to 1 to 3 drops per minute. 3 infants were clinically jaundiced (serum bilirubin $6-8 \mathrm{mg} / 100 \mathrm{ml}$ ) at the time cisternal puncture was performed. These infants had xanthochromic CSF. None of the other infants had jaundice and serum bilirubin was not estimated. Relations between clinical findings in the neurologically abnormal infants and alterations in their CSF are shown in Table VI. The numbers of infants with either apathy or hyperexcitability syndromes having blood-stained CSF with a xanthochromic supernatant, xanthochromic CSF only, or clear and colourless CSF were similar. Therefore, the CSF findings were pooled for further analysis (Table VII). The numbers of

TABLE VI

Clinical findings and alterations in CSF

\begin{tabular}{|c|c|c|c|c|}
\hline \multirow{2}{*}{ Clinical findings } & \multicolumn{4}{|c|}{ No. of infants } \\
\hline & Total & $\begin{array}{l}\text { Bloodstained } \\
\text { CSF }\end{array}$ & $\begin{array}{l}\text { Xanthochromic } \\
\text { CSF }\end{array}$ & $\begin{array}{l}\text { Clear and colourless } \\
\text { CSF }\end{array}$ \\
\hline $\begin{array}{l}\text { Apathy syndrome }+ \\
\text { Impaired sucking and swallowing } \\
\text { responses } \\
\text { Apnoeic attacks } \\
\text { Brisk asymmetric tonic neck response } \\
\text { Absent Moro response } \\
\text { Convulsions } \\
\text { Bulging anterior fontanelle } \\
\text { Retinal haemorrhages } \\
\text { Choroidoretinitis }\end{array}$ & $\begin{array}{r}16 \\
16 \\
13 \\
12 \\
6 \\
1 \\
7 \\
2 \\
1\end{array}$ & $\begin{array}{l}8 \\
8 \\
6 \\
5 \\
3 \\
1 \\
5 \\
1 \\
-\end{array}$ & $\begin{array}{l}5 \\
5 \\
5 \\
5 \\
2 \\
1 \\
1 \\
1\end{array}$ & $\begin{array}{l}3 \\
3 \\
2 \\
2 \\
1 \\
-1 \\
- \\
-\end{array}$ \\
\hline $\begin{array}{l}\text { Hyperexcitability syndrome + } \\
\text { Impaired sucking and swallowing } \\
\text { responses } \\
\text { Apnoeic attacks } \\
\text { Brisk asymmetric tonic neck response } \\
\text { Convulsions } \\
\text { Bulging anterior fontanelle } \\
\text { Retinal haemorrhages }\end{array}$ & $\begin{array}{r}18 \\
18 \\
\\
4 \\
16 \\
4 \\
4 \\
1\end{array}$ & $\begin{array}{l}9 \\
9 \\
2 \\
7 \\
3 \\
2 \\
-\end{array}$ & $\begin{array}{l}6 \\
6 \\
1 \\
1 \\
6 \\
1 \\
1 \\
1\end{array}$ & $\begin{array}{l}3 \\
3 \\
1 \\
3 \\
-1 \\
-\end{array}$ \\
\hline
\end{tabular}


TABLE VII

CSF analysis

\begin{tabular}{|c|c|c|c|c|c|c|c|}
\hline & \multicolumn{3}{|c|}{ No. of infants } & \multicolumn{4}{|c|}{ CSF } \\
\hline & Total & $\begin{array}{c}\text { Birthweight } \\
<2500 \text { g }\end{array}$ & $\begin{array}{c}\text { Birthweight } \\
>2500 \mathrm{~g}\end{array}$ & $\begin{array}{c}\mathrm{RBC} \times 1 \mathrm{C}^{-3} \\
\left(\mathrm{~mm}^{3}\right)\end{array}$ & $\begin{array}{l}\text { WBC } \\
\left(\mathrm{mm}^{3}\right)\end{array}$ & $\underset{(\mathrm{mg} / \mathbf{1 0 0} \mathrm{ml})}{\text { Protein }}$ & $\underset{(\mathrm{mg} / 100 \mathrm{ml})}{\text { Glucose }}$ \\
\hline $\begin{array}{l}\text { Blood-stained fluid (xanthochromic } \\
\text { supernatant) } \\
\text { Xanthochromic fluid } \\
\text { Clear and colourless fluid }\end{array}$ & $\begin{array}{r}17 \\
11 \\
6\end{array}$ & $\begin{array}{l}7 \\
6 \\
1\end{array}$ & $\begin{array}{r}10 \\
5 \\
5\end{array}$ & $\begin{array}{r}91 \cdot 57 \\
+24 \cdot 11 \\
8.69 \\
\pm 7.93 \\
0\end{array}$ & $\begin{array}{r}4 \\
\pm 2 \\
0 \\
0\end{array}$ & $\begin{array}{r}274^{\star} \\
\pm 38 \\
132 \\
\pm 24 \\
69 \\
\pm 9\end{array}$ & $\begin{array}{r}39 \\
\pm 16 \\
42 \\
\pm 2 \\
40 \\
\pm 5\end{array}$ \\
\hline
\end{tabular}

Note: Results are mean \pm SEM or numbers in each group.

$\star$ Significant increase in protein levels in blood-stained fluid compared with either xanthochromic fluid ( $P<0.02$, ' $t$ ' test) or clear colourless fluid $(P<0.005$, ' $t$ ' test).

infants weighing $<2500 \mathrm{~g}$ or $>2500 \mathrm{~g}$ with bloodstained, xanthochromic, or clear and colourless CSF were similar, $50 \%$ of all infants having blood-stained CSF, $32 \%$ xanthochromic, and $18 \%$ clear and colourless. Red and white blood cell counts and glucose levels in CSF in infants with apathy and hyperexcitability syndromes were similar. In the Fig. red blood cell counts in individual specimens of blood-stained CSF of infants with either apathy or hyperexcitability syndromes are shown distributed along a logarithmic axis. The range of values and

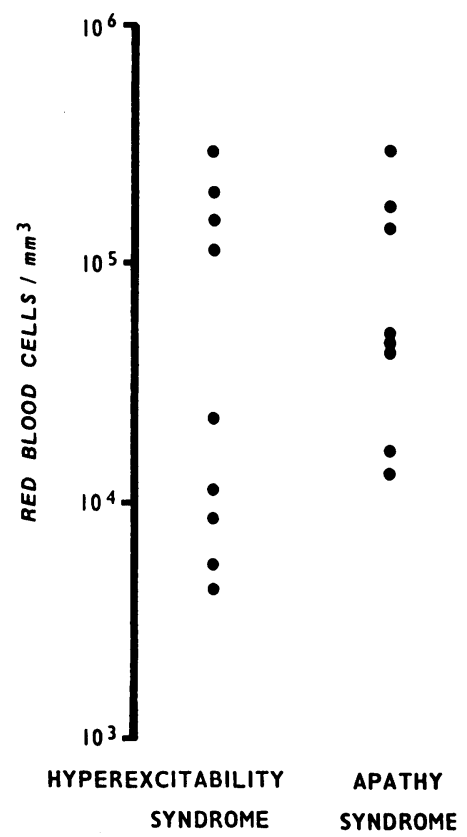

FIG.-Red blood cell counts in blood-stained CSF from infants with either hyperexcitability or apathy syndromes. their distribution in the two groups are similar. No bacteria were cultured from any CSF specimen.

Clinical assessment after cisternal puncture. 3 hours after cisternal puncture infants were examined by the same person (S.W.De S.). On this basis the clinical condition of each infant was considered to have improved, deteriorated, or remained unchanged (Table VIII). Numbers of

\section{TABLE VIII}

Clinical assessment after cisternal puncture

\begin{tabular}{l|c|c|c}
\hline & Improvement & Deterioration & No change \\
\hline $\begin{array}{c}\text { Hyperexcitability } \\
\text { syndrome (18) }\end{array}$ & 6 & - & 12 \\
$\begin{array}{c}\text { Apathy syndrome } \\
\text { (16) }\end{array}$ & 3 & 1 & 12 \\
Total no. (34) & 9 & 1 & 24 \\
\hline
\end{tabular}

infants with either apathy or hyperexcitability syndromes showing improvement 3 hours after cisternal puncture were similar. 1 infant with the apathy syndrome progressively deteriorated and died 4 hours after puncture. The necropsy findings in this infant (Case 3 ) are described below.

Factors associated with neurologically abnormal infants. Smallness-for-dates, prematurity, hypocalcaemia, rhesus haemolytic disease, pneumothorax, congestive heart failure, pneumonia, septicaemia, conjunctivitis, and septic skin lesions were factors associated with these infants (Table IX). Pneumonia was diagnosed by the presence of crepitations and reduced breath sounds in the chest on auscultation and opacities on chest $x$-rays. In 2 infants (Cases 1 and 3 below) evidence of pneumonia was also found at necropsy examination. In 4 
TABLE IX

Factors associated with neurologically abnormal and normal newborn infants

\begin{tabular}{|c|c|c|c|}
\hline & $\begin{array}{l}\text { Hyperexcitability } \\
\text { syndrome }\end{array}$ & $\begin{array}{l}\text { Apathy } \\
\text { syndrome }\end{array}$ & Normal \\
\hline $\begin{array}{l}\text { No. of infants } \\
\text { Factors } \\
\text { Small-for-dates } \\
\text { Prematurity } \\
\text { Hypocalcaemia } \\
\text { Hypoglycaemia } \\
\text { Rhesus haemolytic } \\
\text { disease } \\
\text { Pneumothorax } \\
\text { Congestive heart } \\
\text { failure } \\
\text { Pneumonia } \\
\text { Septicaemia } \\
\text { Conjunctivitis } \\
\text { Skin lesions (septic) }\end{array}$ & $\begin{array}{l}18 \\
4 \\
4 \\
1 \\
2 \\
1 \\
- \\
- \\
- \\
- \\
-\end{array}$ & $\begin{array}{l}16 \\
3 \\
5 \\
- \\
1 \\
1 \\
2 \\
1 \\
6 \star \\
1 \\
1 \\
1\end{array}$ & $\begin{array}{r}14 \\
8 \\
- \\
- \\
1 \\
- \\
- \\
- \\
- \\
- \\
1\end{array}$ \\
\hline
\end{tabular}

*Significant increase in pneumonia in infants with the apathy syndrome compared with either infants with the hyperexcitability syndrome or normal infants $\left(P<0.001, \chi^{2}\right.$ test).

infants pneumonia was diagnosed in the first 24 hours and in the remaining 2 between 24 and 48 hours. Either Esch. coli or coagulase negative Staphylococci were grown from swabs taken from the nose or throat. Viruses were not grown from any of these infants. Results of blood $p \mathrm{H}$ and gas analysis indicated that all these infants were acidotic $(p \mathrm{H}$ $7 \cdot 22 \pm 0 \cdot 03$ SEM, no. $=6$ ), which was of a mixed respiratory and metabolic type. A significant number of infants, 6 of 16 , with the apathy syndrome had pneumonia compared either with none of 18 infants with the hyperexcitability syndrome or none of 49 normal infants.

Necropsy findings. 3 infants, Cases 1, 2, and 3, died at 48,48 , and 96 hours, respectively, after birth. All 3 had the apathy syndrome, reduced sucking and swallowing responses, apnoeic attacks, and absent Moro response, and one (Case 1) had convulsions (tonic and clonic seizures). The CSF collected during life was clear in Case 1, blood-stained in Case 2 , and xanthochromic in Case 3. The following is a summary of the necropsy findings.

Case 1. A male infant, gestational age 36 weeks, birthweight $2580 \mathrm{~g}$. In both lungs there were hyaline membranes in alveolar spaces, bronchopneumonia, and interstitial emphysema. There was also a left pneumothorax. Islet cell hyperplasia was present in the pancreas. In the brain, a few nuclei in the thalamus, putamen, and subthalamic nuclei showed karyolysis; chromatolysis was also seen in some pontine nuclei.
Case 2. A male infant, gestational age 40 weeks, birthweight $3280 \mathrm{~g}$. The heart was enlarged and there were several defects-ventricular septal defect, atresia of the aortic valve and the proximal part of the aorta up to the ductus arteriosus, and a large pulmonary artery trunk. There was also a large subarachnoid haemorrhage and haemorrhage into the tentorium cerebelli and falx cerebri.

Case 3. A male infant, gestational age 36 weeks, birthweight $2380 \mathrm{~g}$. There were large intraventricular haemorrhages and blood had also extended into the subarachnoid space. Both leaflets of the tentorium cerebelli contained a fairly large haematoma which had extended into the falx cerebri. In addition, there was bilateral pneumonia.

\section{Neurological abnormalities during the first} year. 30 infants who previously had abnormal neurological signs and 49 normal infants were seen as outpatients during the first year. 1 infant with abnormal neurological signs in the newborn period could not be followed up because the parents had left the area. Among the remaining infants 1 died at 3 months, a 'cot death' associated with bronchopneumonia, and 5 had some form of neurological abnormality during the first year subsequent to the newborn period. These were convulsive seizures, spastic diplegia, hypertonia with coarse tremor, or hydrocephalus (Table X).

Convulsive seizures occurred at 3 months and 2 months, respectively, in 2 infants with the hyperexcitability syndrome. Another infant with the hyperexcitability syndrome developed hypertonia and coarse tremor which were diagnosed at 3 months. All these infants were born at term (birthweights $2840-3110 \mathrm{~g}$ ) with birth scores of 3 ,

TABLE $\mathbf{X}$

Neurological abnormalities during the first year subsequent to the newborn period

\begin{tabular}{|c|c|c|c|}
\hline & $\begin{array}{l}\text { Hyperexcitability } \\
\text { syndrome }\end{array}$ & $\begin{array}{l}\text { Apathy } \\
\text { syndrome }\end{array}$ & Normal \\
\hline $\begin{array}{l}\text { No. of infants } \\
\text { Neurological } \\
\text { abnormalities } \\
\text { Convulsive seizures } \\
\text { Spastic diplegia } \\
\text { Hypertonia and } \\
\text { coarse tremor } \\
\text { Hydrocephalus }\end{array}$ & $\begin{array}{l}2 \\
- \\
1 \\
-\end{array}$ & $\begin{array}{l}\overline{1} \\
\overline{1}\end{array}$ & $\begin{array}{l}- \\
- \\
-\end{array}$ \\
\hline
\end{tabular}

Note: Significant increase in neurological abnormalities after the newborn period in infants who had hyperexcitability or apathy syndromes compared with normal infants $\left(P<0.025, \chi^{2}\right.$ test). 
and had previous fetal distress. 1 infant with convulsive seizures had blood-stained CSF and the remaining 2, either with convulsive seizures or flexor hypertonia and coarse tremor, had xanthochromic CSF.

Among infants with the apathy syndrome, 1 developed spastic diplegia and 1 hydrocephalus. Spastic diplegia was diagnosed at 6 months and hydrocephalus at 4 months. The infant with spastic diplegia was born prematurely (36 weeks) and was also small-for-dates $(2350 \mathrm{~g})$. He had a birth score of 2, blood-stained CSF, absent sucking, swallowing, and Moro responses, and pneumonia. The other infant who had hydrocephalus was born at term and weighed $3240 \mathrm{~g}$ at birth. He also had a birth score of 2 but had clear and colourless CSF and choroidoretinitis. Extensive investigations failed to reveal evidence of viral or toxoplasma infection. In this context it is noteworthy that none of the infants with blood-stained CSF developed hydrocephalus.

None of the normal infants had neurological abnormalities during the first year. In comparison, a significant number of infants with the apathy and hyperexcitability syndromes had neurological abnormalities during the first year.

\section{Discussion}

In the present study neurologically abnormal infants presented with either the apathy or hyperexcitability syndrome. The syndromes represented well-defined clinical states which were recognized in both premature (33-36 weeks) and term infants. However, since the number of infants studied was small the results have to be interpreted cautiously.

Although fetal distress occurred both in fetuses who were subsequently neurologically normal or abnormal there was a significantly greater percentage of infants with the hyperexcitability syndrome who had a history of fetal distress. Fetal distress in man is associated with prenatal asphyxia (Tipton and Shelley, 1971): in animals, severe prenatal asphyxia results in brain damage (Myers, 1972; Adamsons and Myers, 1973); by implication, the brain damage resulting from prenatal asphyxia is more likely to present with the hyperexcitability syndrome than the apathy syndrome.

The condition one minute after birth was a good guide to the early neurological status of the infant. All infants whose condition was defined as poor at birth became neurologically abnormal, most developing the hyperexcitability syndrome. However, when the condition was 'good' at one minute, all were subsequently normal. Though infants developing the apathy syndrome had mainly scores of 2-4, the numbers studied were too few to make the incidence of this association significant. It is reasonable to suggest, therefore, that infants whose condition is 'poor' immediately after birth have previously sustained brain damage since all such infants in this study subsequently developed abnormal neurological signs.

Among the many clinical findings associated with the abnormal infants (Table V) three were remarkable: apnoeic attacks, absent Moro response, and absent sucking and swallowing responses. Apnoeic attacks and an absent Moro response were seen predominantly in infants with the apathy syndrome and may have been related to the depressed state of CNS function. These infants may have a worse prognosis since frequent and severe apnoeic attacks may contribute to further brain damage by causing hypoxia, hypercapnia, and acidosis. The 3 infants who died manifested the apathy syndrome associated with apnoeic attacks, absent Moro response, and absent sucking and swallowing responses. It is worth noting that in a study by Brown et al. (1972), 15 of 40 neurologically abnormal infants who required tube-feeding and 11 of 16 neurologically abnormal infants with an absent Moro response died. Absent sucking and swallowing responses were a feature of all the neurologically abnormal infants in this study and they therefore required feeding through a nasogastric tube and also intravenously.

A confident diagnosis of pneumonia may be difficult in a newborn infant. Pneumonia was diagnosed in this study if a baby had the appropriate clinical and radiological findings associated with bacterial pathogens in the upper respiratory tract and the diagnosis led to systemic antibiotic treatment. Pneumonia occurred only in infants with the apathy syndrome and may have been caused by either infection (MacGregor, 1939; Langley and Smith, 1959; Fujikura and Froehlich, 1967) or aspiration of gastric contents (Rhaney and MacGregor, 1948; Barrie, 1968). The mixed acidosis observed in infants with pneumonia could have contributed further to their brain damage.

A cisternal puncture is useful for diagnosing intracranial haemorrhage, but certain precautions are necessary to make it a safe procedure (Davies et $a l .$, 1972). Large volumes of CSF can be removed and reduction in intracranial tension may benefit the patient. The presence of intracranial haemorrhage diagnosed in 1 patient and excluded in another by cisternal puncture was later confirmed at necropsy. However, the third patient had xanthochromic CSF but necropsy later revealed large intraventricular and subarachnoid haemorrhages. In 9 patients the 
clinical improvement which followed cisternal puncture may have been due to reduction in intracranial tension. However, further studies including precise measurements of intracranial tension and suitable controls will be necessary before this relation can be firmly established. The finding of xanthochromic or blood-stained CSF unfortunately did not help in the diagnosis of the type of neurological abnormality. This was not altogether unexpected since bleeding into the subarachnoid space at birth is often associated with asphyxia and prematurity (Gröntoft, 1954; Haller, Nesbitt, and Anderson, 1956; Gruenwald, 1951; Schwartz, 1961).

There is an association between the apathy and hyperexcitability syndromes in newborn infants and neurological abnormalities during later development. In the present study, neurological abnormalities were diagnosed during the first year in 5 of 30 infants who had the apathy or hyperexcitability syndrome in the newborn period, but did not occur in normal infants. In studies by Prechtl (1965) and Schulte et al. (1965) an even higher incidence of neurological abnormalities in early childhood were observed among newborn infants with apathy or hyperexcitability syndromes.

We are grateful to Professors J. A. Davis for helpful advice and F. A. Langley who was responsible for the necropsy examinations.

\section{REFERENCES}

Adamsons, K., and Myers, R. E. (1973). Perinatal asphyxia: causes, detection and neurologic sequelae. Pediatric Clinics of North America, 20, 465.

Amiel-Tyson, C. (1969). Cerebral damage in full-term newborn, aetiological factors, neonatal statis and long-term follow-up. Biologia Neonatorum, 14, 234.

Barrie, H. (1968). Effect of feeding on gastric and oesophageal pressures in the new-born. Lancet, 2, 1158.

Beintema, D. J. (1968). A Neurological Study of Newborn Infants, p. 27. Clinics in Developmental Medicine No. 28. Spastics International Medical Publications and Heinemann, London.

Brown, J. K., Cockburn, F., and Forfar, J. O. (1972). Clinical and chemical correlates in convulsions of the newborn. Lancet, 1 , 135.

Butler, N. R., and Alberman, E. D. (1969). Perinatal Problems. Second Report of the 1958 British Perinatal Mortality Survey, p. 331. Livingstone, Edinburgh and London.

Dargassies, S. S-A. (1962). Le nouveau-né à terme: aspect neurologique. Biologia Neonatorium, 4, 174.

Davies, P. A., Robinson, R. J., Scopes, J. W., Tizard, J. P. M., and Wigglesworth, J. S. (1972). Medical Care of Newborn Babies, p. 280. Clinics in Developmental Medicine Nos. 44/45. Spastics International Medical Publications and Heinemann, London. del Mundo-Vallarta, J., and Robb, J. P. (1964). A follow-up study of newborn infants with perinatal complications. Neurology, 14, 413.

Donovan, D. E., Coues, P., and Paine, R. S. (1962). The prognostic implications of neurologic abnormalities in the neonatal period. Neurology, 12, 910.

Fujikura, T., and Froehlich, L. A. (1967). Intrauterine pneumonia in relation to birth weight and race. American fournal of Obstetrics and Gynecology, 97, 81 .

Gröntoft, O. (1954). Intracranial haemorrhage and blood-brain barrier problems in the newborn. Acta Pathologica et Microbiologica Scandinavica, Suppl. C, 1.

Gruenwald, P. (1951). Subependymal cerebral hemorrhage in premature infants, and its relation to various influences at birth. American fournal of Obstetrics and Gynecology, 61, 1285.

Haller, E. S., Nesbitt, R. E. L., and Anderson, G. W. (1956). Clinical and pathological concepts of gross intracranial hemorrhage in perinatal mortality. Obstetrical and Gynecological Survey, 11, 179.

Langley, F. A., and Smith, J. A. McC. (1959). Perinatal pneumonia. Fournal of Obstetrics and Gynaecology of the British Empire, 66, 12.

MacGregor, A. R. (1939). Pneumonia in the newborn. Archives of Disease in Childhood, 14, 323.

Meulemans, O. (1960). Determination of total protein in spinal fluid with sulphosalicylic acid and trichloroacetic acid. Clinica Chimica Acta, 5, 757.

Myers, R. E. (1972). Two patterns of perinatal brain damage and their conditions of occurrence. American fournal of Obstetrics and Gynecology, 112, 246.

Prechtl, H. F. R. (1960). The long term neurological value of the examination of the newborn infant. In Child Neurology and Cerebral Palsy, p. 69. Ed. by R. D. Mac Keith, E. ClaytonJones, and M. C. O. Bax. Clinics in Developmental Medicine No. 2. National Spastics Society and Heinemann, London.

Prechtl, H. F. R. (1965). Prognostic value of neurological signs in the newborn infant. Proceedings of the Royal Society of Medicine, 58, 3.

Prechtl, H. F. R. (1967). Neurological sequelae of prenatal and perinatal complications. British Medical fournal, 4, 763.

Prechtl, H. F. R. (1968). Neurological findings in newborn infants after pre- and paranatal complications. In Nutricia Symposium, Aspects of Praematurity and Dysmaturity, p. 303 . Ed. by J. H. P. Jonxis, H. K. A. Visser, and J. A. Troelstra. Stenfert Kroese, Leiden.

Rhaney, K., and MacGregor, A. R. (1948). Pneumonia in the newborn resulting from the inhalation of gastric contents. Archives of Disease in Childhood, 23, 254.

Robinson, R. J. (1966). Assessment of gestational age by neurological examination. Archives of Disease in Childhood, 41, 437.

Schulte, F. J., Filipp, E., and Michaelis, R. (1965). Neurologie des Neugeborenen. II. Die Prognose von Funktionsstörungen des zentralen Nervensystems beim Neugeborenen. Zeitschrift für Kinderheilkunde, 93, 264.

Schwartz, P. (1961). Birth Injuries of the Newborn, p. 1. Karger, Basle.

Smithells, R. W. (1961). Prognostic value of neurological examinations in the newborn. Cerebral Palsy Bulletin, 3, 7.

Tipton, R. H., and Shelley, T. (1971). An index of fetal welfare in labour. Fournal of Obstetrics and Gynaecology of the British Commonwealth, 78, 702 .

Correspondence to Dr. S. W. De Souza, Department of Child Health, University of Manchester, St. Mary's Hospital, Manchester M13 0JH. 